\title{
The problem with CBT \\ (\& why constructivism makes things worse)
}

\author{
Leesa Wheelahan \\ Griffith University \\ Australia $^{1}$
}

\section{Introduction}

The aim of this paper is to develop and extend a social realist critique of competency based training (CBT). Its key argument is that knowledge must be placed at the centre of curriculum, and that because CBT does not do this, it excludes working class students from access to powerful knowledge. Developing this argument reveals that constructivist critiques of CBT not only miss the point, they are part of the problem. The paper argues that this is because the relationship between constructivism and instrumentalism structured the development of CBT in the vocational education and training (VET) sector in Australia, even though they are distinct theoretical approaches to curriculum. Constructivist discourses were appropriated and reworked through the prism of instrumentalism, thereby contributing to the justification and legitimation of CBT, but also to its continuing theorisation and development. The basis for the appropriation of constructivism by CBT is that both emphasise the contextual, situated and problem-oriented nature of knowledge creation and learning and in so doing, sacrifice the complexity and depth of theoretical knowledge in curriculum in favour of 'authentic' learning in the workplace. Consequently, in developing its critique of $\mathrm{CBT}$ and the instrumentalist learning theories that underpin it, constructivism misses the main point, which is that theoretical knowledge must be placed at the centre of curriculum in all sectors of education, and that access to knowledge is the raison d'être of education (Young 2008).

This is not just an esoteric argument; there are real practical consequences for students and society. CBT is hegemonic and pervasive in VET in Australia, perhaps to a greater extent than in many other countries. ${ }^{2}$ Australia has two sectors of tertiary education; a higher education (HE) sector and a VET sector. Training packages are the mandated form of publicly funded VET qualifications in Australia and they are based on CBT models of curriculum. All publicly funded VET qualifications must be based on training packages where they exist or on 'industry-specified' units of competency in their absence. Training packages are the equivalent of the British National Vocational Qualifications (NVQs). If CBT is structured so that students are not provided with access to theoretical knowledge, at least to the same level as those

\footnotetext{
${ }^{1}$ Contact details: School of Education \& Professional Studies, Mt Gravatt campus, Griffith University, Brisbane, QLD 4111 Australia. Email: l.wheelahan@griffith.edu.au. Ph: +61 737356843.

2 In 2005, 78.24\% of outcomes achieved by students were based on training package units of competency and 21.75\% were based on modules, which are not competency-based (DEST 2006a: derived from Table 1.10). The latter mostly consist of further education modules, but further education programs are increasingly marginal and their future is threatened unless they can demonstrate they contribute to labour market outcomes.
} 
undertaking HE qualifications, then this represents a mechanism for social stratification, because VET in Australia is over-represented by students from lower socio-economic backgrounds, whereas HE is over-represented by students from high socio-economic backgrounds (Foley 2007).

The argument in this paper is developed through drawing on the sociology of Basil Bernstein and the philosophy of critical realism as complementary modes of analysis. While all social realists acknowledge their theoretical debt to Bernstein, not all draw on critical realism, so this paper is part of a continuing discussion within social realism about the nature of knowledge and its place in the curriculum. However, this discussion proceeds on the basis of substantive agreement, which is that all students need to be provided with access to theoretical knowledge so that they can navigate the boundaries between theoretical and everyday knowledge and between different kinds of theoretical knowledge.

The first section draws on Bernstein and critical realism to analyse the nature of knowledge, the complexity of the social and natural worlds, the relationship between knowledge and the social and natural world, and the way in which the structures of knowledge are implicated in processes of knowledge production and acquisition. This framework is then used in the remainder of the paper to critique CBT and to demonstrate the way in which constructivism aids and abets CBT because each has problematic ontological premises that are reflected in their theories of curriculum. It outlines the structure of CBT and how it denies students access to knowledge; the way in which CBT appropriates progressivism for its continued justification; the ontological premises of CBT that allow it do this; and the similarities and differences between CBT and constructivism. Both are critiqued for their focus on the contextual, and the implications for curriculum are considered.

\section{The nature of knowledge}

Basil Bernstein (2000) argued that fair access to theoretical knowledge was important for democracy because it is the means society uses to conduct its conversation about itself and about what it should be like. Society uses theoretical knowledge to imagine alternative futures through thinking the unthinkable and the not-yet-thought. This is why theoretical knowledge is socially powerful knowledge. Access to abstract theoretical knowledge is thus a question of distributional justice, and curriculum in all qualifications should be structured so that they provide students with this access.

Access to theoretical knowledge is becoming more important in work. Individuals need to draw on increasingly complex knowledge as a consequence of changes to society, work and technology. Young (2008: 146) argues that while all jobs require context-specific knowledge, "many jobs also require knowledge involving theoretical ideas shared by a 'community of specialists'” located within the disciplines. Workers need to be able to use theoretical knowledge in different ways and in different contexts as their work grows in complexity and difficulty. This means that occupational progression is strongly related to educational progression, because education is the main way in which most people are provided with access to disciplinary knowledge. It also means that all qualifications should provide students with the disciplinary knowledge they need to study at a higher level within their field 
in addition to immediate occupational outcomes. VET qualifications do not do this because of their current exclusive focus on workplace-specific outcomes.

Critical realists argue that the (natural and social) world is complex and stratified. For example, Collier (1998: 263) explains everything is governed by the law of physics; some, but not all things are governed by the laws of biology; and more recently, some but not all things are governed by the law of capitalist economics. In this instance, these different strata (and others not identified here) interact to make factory production possible. It is a relational philosophy because it examines the interplay between different objects and strata, arguing "that the world is characterised by emergence, that is situations in which the conjunction of two or more features or aspects gives rise to new phenomena, which have properties which are irreducible to those of their constituents, even though the latter are necessary for their existence" (Sayer 2000: 12). For example, even though a society could not exist without people, society is more than the sum of its parts and it is not possible to add up all the individuals to understand the way society is structured and its dynamics, and the impact it in turn has on people.

It is necessary to identify three levels of reality in the social and natural worlds, and as will be demonstrated later, the central problem with both CBT and constructivism is that they fail to do so. The three levels are the real, actual and empirical. This is illustrated in Table 1.

Table 1: The domains of the real, actual \& empirical

\begin{tabular}{|l|l|l|l|}
\hline & Domain of Real & Domain of Actual & Domain of Empirical \\
\hline Mechanisms & $\checkmark$ & & \\
\hline Events & $\checkmark$ & $\checkmark$ & \\
\hline Experiences & $\checkmark$ & $\checkmark$ & $\checkmark$ \\
\hline
\end{tabular}

Source: Bhaskar (1998a: 41)

The domain of the real consists of underlying causal mechanisms. An example of a causal mechanism in the social world is class, while gravity is an example in the natural world. Generative mechanisms interact in open systems, and this means that some cancel each other out, or change the way in which they act. Not everything that could happen does happen. For example, Sayer (1992: 110) says that we don't need to explode neutron bombs to know their causal liabilities. Sayer (2000: 11) explains that "Realists therefore seek to identify both necessity and possibility or potential in the world - what things must go together, and would could happen, given the nature of the objects."

The interaction of generative mechanisms gives rise to events, which Bhaskar (1998a: 41) describes as the domain of the actual, where things actually happen. Events are always co-determined by multiple stratified generative mechanisms, and as such, outcomes cannot be fully predicted in advance. Some events can be perceived while others cannot. The tree does indeed make a sound when it falls in the forest, even if there is no-one there to hear it. Whether or not we perceive events is an empirical question, one that is continually reshaped by science as we discover ways to empirically observe events that previously were only discernable through their effects. The third domain is the domain of the empirical, which "is comprised only of experiences" (Collier 1994: 45). This means that it must have been generated in the 
domain of the real and taken place in the domain of the actual. This depth ontology allows us to see that the world is not reducible to what we experience or what happens, there is much that could happen and understanding this is necessary if we are to think the unthinkable and the not-yet-thought.

Even though knowledge is about objects it is not the same as those objects. There is no direct correspondence between objects and knowledge because knowledge is socially produced and mediated, and has its own conditions for its existence and causal properties. Bernstein's analysis adds depth to critical realism because he explores the causal properties of the structures of knowledge, and the implications for the way such knowledge is produced and acquired.

Bernstein (2000)argued that theoretical knowledge differs from everyday knowledge because each is embedded in a different system of meaning and each has a different structure. He characterised abstract theoretical knowledge as vertical discourse, and everyday or 'mundane' knowledge as horizontal discourse. Theoretical knowledge is general, principled knowledge. It is organised as a vertical discourse which is, to a greater or lesser extent, hierarchically structured. It consists of "specialised symbolic structures of explicit knowledge" in which the integration of knowledge occurs through the integration of meanings and not through relevance to specific contexts (Bernstein 2000: 160). Students need access to the disciplinary system of meaning as a condition for using knowledge in contextually specific applications. For example, students need access to mathematics as a condition for understanding and applying particular formulas, and if they are to use these formulas in different contexts. In contrast, everyday knowledge is organised as a horizontal discourse, which consists of segmented knowledge structures. It is particularised knowledge, because its selection and usefulness is determined by the extent to which it is relevant in a particular context (Gamble 2006). This is the tacit, context-dependent knowledge of the workplace. Bernstein (2000: 157) explains that everyday knowledge is "likely to be oral, local, context dependent and specific, tacit, multi-layered, and contradictory across but not within contexts.”

Theoretical knowledge organised through disciplinary frameworks is also strongly classified knowledge because the boundaries between it and everyday knowledge are clearly defined, and because each of the academic disciplines has a specialised language and strong boundaries that insulates it from other disciplines. In contrast, everyday knowledge is weakly classified because its contextual relevance is of primary importance. The way an academic discipline is structured has implications for the way in which it is translated for pedagogic transmission. Induction into a particular academic discipline requires induction into its system of meaning, which may have implications for the way knowledge is selected, sequenced, paced and evaluated. This is the 'how' of pedagogic practice, and Bernstein refers to this as the process of framing. The more hierarchical a body of knowledge (for example, physics) the more likely it is that pedagogy will need to be strongly sequenced because students need to understand what came before in order to understand what comes after (Muller 2006).

Students need to be inducted into disciplinary systems of meaning as the basis of developing the 'recognition' rules they need to recognise the distinction between vertical and horizontal discourses, and between different types of vertical discourses 
so that they can, for example, distinguish between physics and chemistry, or microeconomics and sociology (Bernstein 2000). In general, knowledge that is strongly classified into disciplinary frameworks provides students from disadvantaged backgrounds with more access to theoretical knowledge than weakly classified knowledge. Knowledge that is strongly classified and framed explicitly signals the boundaries between different areas of knowledge, and the way it is sequenced, paced and evaluated, whereas these relations are rendered opaque in knowledge that is weakly classified and framed. Consequently, collapsing the boundary between vertical and horizontal discourse is problematic because it denies students epistemic access to each kind of knowledge, and as a consequence, it denies students social access to this knowledge. This is the heart of the problem with both CBT and constructivism.

\section{Structure of CBT $\mathcal{E}$ how it excludes from access to knowledge}

CBT excludes students from access to disciplinary knowledge because it only provides students with access to contextually specific applications of knowledge, and not the system of meaning in which it is embedded. Units of competency describe workplace tasks or roles. Competency is defined as the application of specified knowledge, skill and attitudes needed to undertake a work role or task to the required standard in the workplace (DEST 2006b: 69). Units of competency include, among other things, elements of competency (that break down the unit of competency into demonstrable and assessable outcomes or actions), performance criteria that specify the required level of performance, required knowledge and skills, a range statement that describes the contexts and conditions in which the performance criteria apply, and evidence guides that describe the underpinning knowledge and skills that need to be demonstrated (assessed) to prove competence (DEST 2006b: 117). The 'rules' surrounding training packages and units of competence are that while knowledge must be included, it should be in context, and should "only be included if it refers to knowledge actually applied at work” (DEST 2006b: 114). Furthermore, "Units of competency that integrate knowledge into the overall performance specification of the unit and the assessment process advice should fully include all relevant knowledge as it is applied in a work role" (DEST 2006b: 140, emphasis added).

This demonstrates that knowledge is included, but it is only contextually specific knowledge which has been delocated from the system of meaning in which it is embedded. It is only included if it is directly related to a work role. For example, 'Develop \& update the legal knowledge required for business compliance' is a unit of competency in the Advanced Diploma of Hospitality Management, which, according to the unit descriptor, "deals with the skills and knowledge required to ensure business compliance with legislation governing the tourism and hospitality industries" (CoA 2002: 477). This is quite different to the first year 'Business Law' subject in the Bachelor of Business (Hospitality Management) at the same university in Victoria which offers the aforementioned advanced diploma, which aims to "provide students with an understanding and awareness of the basic principles of Contract Law, a familiarity with relevant case law and an introduction to the statutory provisions pertinent to the course." It explains that the purpose is to help students "develop an 
understanding of legal reasoning as it applies to the analysis of contractual relationships.” 3

CBT translates knowledge from being general and principled knowledge to particularised knowledge, because its selection and usefulness is determined by the extent to which it is relevant in a particular context. Students thus have access to knowledge in its particularised form, but are not provided with the means to relate it to its general and principled structure and system of meaning.

Supporters of training packages argue that they merely specify the outcomes of learning and not the processes of learning, which means that 'providers' and teachers are free to develop a curriculum approach that most suits their 'clients'. For example, Schofield and McDonald (2004a: 2) say that "Consistent with their outcomes-based orientation, Training Packages are silent on how teachers and trainers should or could design the curriculum to achieve these outcomes." However, the Training Package Development Handbook (DEST 2006b: 126) says that: "Performance criteria must be expressed precisely to enable appropriate training and assessment." It is clear that training packages do shape teaching and learning, and that they constitute an important component of curriculum, because they specify what is to be taught and, in broad terms, how it should be assessed. The point of training packages was that they would reshape teaching and learning in VET so that it was more 'industry responsive'. Students are enrolled in, taught within the framework of, and assessed on the basis of, units of competency. This is curriculum by any other name.

\section{The appropriation of progressivism for continued justification of CBT}

The introduction of CBT in VET in the 1980s and 1990s in Australia was a key component of neo-liberal reforms that sought to create a 'training market' and an 'industry-led' training system as part of broader industry restructuring and microeconomic reform (Goozee 2001: 62). Its introduction was mediated through the selective use of the emancipatory language associated with the developmental discourse of the 'new vocationalism', which was tied to new conceptions about work and society (Bates et al. 1998). However, in Australia as in England, the 'new vocationalism' of the 1970s and early 1980s was transformed into 'controlled vocationalism' that granted increased control to the state and to employers in specifying the outcomes of VET (Bates et al. 1998: 114). Rather than problematising the nature of work, the outcomes of education were redefined as unproblematic 'descriptions' of the skills needed by employers.

The move from the new vocationalism to controlled vocationalism occurred despite the language of empowerment that described the way students and teachers would be empowered; language that was used at the beginning of the introduction of CBT and in its subsequent implementation as NVQs in England and as training packages in Australia. Indeed, a stronger argument is possible: the language of empowerment facilitated the move from the new vocationalism to controlled vocationalism. This

\footnotetext{
${ }^{3}$ Source: http://wcf.vu.edu.au/Handbook/DisplaySubjectDetails.cfm?SubjectID=32925 accessed 20 June 2008.
} 
language is still being used in Australia. Students are putatively empowered not just because they can 'choose' what, when and how they will study, but also because learning is now a negotiated activity in which "learners have a part to play in developing their own learning processes, contexts and outcomes" (Smith and Blake 2005: 6). In practice, however, the freedom that is entailed is limited to the way in which "the tightly prescribed learning objectives are to be achieved" (Bates 1998: 188).

The language of empowerment is not just limited to students. Teachers are putatively empowered because training packages allow teachers and 'trainers' to creatively develop and apply their pedagogical skills and knowledge and "to develop and promote their expertise as flexible learning managers" (Scollay 2000). It is clear, however, that teachers do not feel empowered. In their high level review of training packages, Schofield and McDonald (2004b: 27) found that there was an "unacceptably high level of confusion amongst educators in particular about the relationship between Training Packages and teaching, learning and assessment." Furthermore, it wasn't just that teachers do not understand training packages, they are also hostile to them, and Schofield and McDonald (2004b: 33) argued that this legacy needed to be dealt with if training packages were to be based on a 'new settlement'. Consequently, the 'problem' is one of implementation, and while some responsibility is directed towards broad policy and the way that it is implemented, most is steeped in a deficit discourse around teachers' skills. The language of progressivism is used to describe the kinds of changes teachers need to make, and to simultaneously construct the discourse around their deficits. They need to be innovative, flexible and creative, be able to understand and apply adult learning theory and principles and empower learners through this process (Mitchell et al. 2006).

How are we to understand this? Jones and Moore (1995: 81) explain that educational policy must be located within the political context in which it arises, and this helps us to understand the way in which the progressivism of the new vocationalism was transformed into controlled vocationalism. They explain that elements of progressive discourse are selectively appropriated and reassembled so that the appropriated discourse is ideologically congruent with the broader regulative discourse shaped by the particular model of social order (in this case, neo-liberalism) pursued by government policy (Jones and Moore 1995).

The policy discourse of competence borrowed concepts and language from theories that were originally developed within academic disciplines, and then reassembled within the framework of "an approach appropriate to the particular objectives of the agency assembling it" " (Jones and Moore 1995: 83). The introduction of CBT in England (and in Australia) incorporated " 'the world of work' according to its own particular principles and rules” (Jones and Moore 1995: 84).

Elements of progressivism were selectively drawn from humanism and reassembled within instrumentalism at the broad policy level, while elements of constructivism that emphasised situated learning and a focus on the student were selectively used in the implementation of CBT with its focus on workplace learning. Vocationalism drew from progressivism a rejection of "the centrality of disciplinary knowledge and school subjects in definitions of the curriculum” (Bates et al. 1998: 111). Progressivism (in the tradition of Rousseau, Blake and the Romantic movement) was concerned 
primarily with the development of the intrinsic capacities of the child/student, and so the task of the teacher was not to instil disciplinary knowledge, but to "expose students to situations in which they could construct their knowledge of the world" (Bates et al. 1998: 111). Bloomer (1998: 168) explains that the reworked progressivism drew the language of "consumer rights, freedom and individuality" from the liberal market ideologies that were driving the new vocationalism, because these were seen as "inherently and morally good." It was however, the instrumentalist policy objectives that dominated and shaped borrowed concepts.

\section{CBT policy as pastiche - the ontology of CBT}

The theoretical premise within instrumentalism that allows it to appropriate from constructivism is the way in which CBT divorces learning outcomes from processes of learning. Such appropriation is also possible because of theoretical commonalities between instrumentalism and constructivism, and this is addressed in the next section.

CBT is a form of empirical realism based on atomism in ontology and epistemology, in which the 'real' consists of discrete, atomistic events that can be translated into unproblematic (empirical) descriptions of those events (Bhaskar 1998a). This is expressed in units of competency, which are unproblematic descriptions of workplace roles or tasks. The ontology of CBT means that each of the constituent components of the model can be considered independently of the other and adjusted as appropriate to 'fix' deficiencies in the model. The model is then reassembled through an aggregative process rather than a relational one in which the constituent components are changed by their relationship to the whole and to each other.

For example, the design of units of competency has been augmented to accommodate concerns about, among other things, the inclusion of underpinning knowledge and to ensure that a broad range of contexts was specified in units of competency as insurance against overly narrow training (Rumsey 2003: 13 - 15). However, the underlying definition of competency has not changed fundamentally in Australia since 1992, although the words may have slightly changed. The 'solution' to every perceived deficiency was to add required and optional components to the model and tight specifications for their inclusion.

This process of augmentation and aggregation makes it possible for supporters of training packages to distinguish between learning outcomes, curriculum, pedagogy and the resources used to support teaching and learning. If each is considered independently rather than relationally, then it is possible to invest each with differing content. In the case of CBT proselytisers, the outcomes of learning are held constant while other aspects are changed as needed. This is necessary because the underlying premise of CBT is that employers (or more charitably and inclusively, sometimes 'industry') should determine what is needed in the workplace. ${ }^{4}$ This is what an industry-led VET system is supposed to mean, with the result that this component of the model - industry specification of outcomes - is not negotiable.

\footnotetext{
${ }^{4}$ In fairness, Schofield and McDonald, while agreeing with the notion of an industry-led system, do not restrict this to employers. Their approach is far more corporatist and friendly to unions.
} 
The result is policy that uses as its justification and source of legitimation a pastiche of theories and approaches that draw from sometimes opposing theoretical premises, then blended through processes of recontextualisation so that constructivist theories of learning are mobilised to support human capital objectives, even though human capital theory is based on the self-maximising rational economic individual. Individualistic theories of learning styles (that ascribe learning styles as relatively fixed attributes of individuals) are unproblematically blended with theories that emphasise learning as a participative process (in which the construction of meaning is a shared process). ${ }^{5}$ This process of selection, augmentation, blending and incorporation is achieved through the principles derived from the broader human capital policy context.

\section{Why CBT can draw on constructivism in theorising}

The relationship between instrumentalism and constructivism makes CBT possible not just at the level of its legitimation and justification, but also in its theorisation and development. Even though constructivists differ among themselves about the nature of contexts (Edwards and Miller 2007), they share a common concern about context with instrumentalists, and with the contextual, situated and problem-oriented nature of knowledge creation and learning. Both constructivists and instrumentalists sacrifice the complexity and depth of knowledge (including vocational knowledge) in curriculum in favour of 'authentic' learning in the workplace. Both could agree with the statement that: "Current thinking emphasises knowledge constructed as practical, interdisciplinary, informal, applied and contextual over knowledge constructed as theoretical, disciplinary, formal, foundational and generalisable" (Chappell et al. 2003: 7). Both privilege the workplace as the site of learning and knowledge production at the expense of disciplinary knowledge, based on the assumption that the process of creating, acquiring and applying knowledge are the same. Both emphasise the context specific features of knowledge rather than its decontextualised features.

As a consequence of their emphasis on the contextual, both posit a 'flattened' ontology in which 'the real' exists at the level of events and experiences (Bhaskar 1998b), and both reduce knowledge to experience although they do so in different ways (Young 2008; Moore 2007). Both omit from their analysis the generative mechanisms in the domain of the real and the emergent outcomes that ensue from their necessary and contingent interactions in open systems to result in a stratified, complex reality. Consequently, neither has the capacity to distinguish between contexts by identifying commonalities and differences, or to identify features of the context that are necessary and those that are contingent because all aspects of the context are equal. The structuring mechanisms of events and experiences are thus rendered invisible, so any analysis of context is necessarily always partial and incomplete.

Because experience is the basis of knowledge, both minimise the differences between knowledge acquired at work and that acquired in education. This enables both to emphasise the commensurability of vertical and horizontal discourses rather than their differences because each consists of experiences that form the basis of knowledge. Indeed, a stronger argument can be made; both privilege horizontal discourses over

\footnotetext{
${ }^{5}$ See Smith and Blake (2005: 3-4) for a particularly illustrative example of this.
} 
vertical discourses because of their emphasis on 'authentic' learning in the workplace and in sites other than the academy, because it is in the former that knowledge can be contextualised and applied. Knowledge is not valued unless it has application in the workplace or can be used to solve a problem, as in problem-based learning approaches to curriculum.

Where the existence and necessity of codified knowledge is admitted, both see it in instrumental terms and subordinate to 'authentic learning' rather than as systemised, structured bodies of knowledge. These structures have their own emergent properties that have pedagogic implications for the way students engage with this knowledge, and for its selection and sequencing. Consequently, both are unable to theorise the relationship between theoretical knowledge and knowledge acquired in the workplace. This is a problem because, as Young (2008: 144) explains, it is "the connections between the codified knowledge of the college-based curriculum and the tacit and often un-codifiable knowledge that is acquired in workplaces that is the basis for what is distinctive about vocational knowledge." The boundaries between the two sites and the kinds of knowledge in each constitute the basis for navigating between the two, yet neither instrumentalism nor constructivism can adequately theorise this relationship because they collapse the distinction between the kinds of knowledge available in each.

\section{Instrumentalism}

Bernstein's insights allow us to see that in tying knowledge to workplace tasks and roles within units of competency, CBT fundamentally transforms the nature of knowledge by delocating it from the vertical discourse in which it is classified and relocating it into a horizontal and segmented knowledge structure. This changes the nature of knowledge and the processes through which it is acquired. Rather than integration of meanings characteristic of vertical discourses, we have integration within a context characteristic of horizontal discourses. It results in a segmental pedagogy in which, as Maton (2007: 6) explains, "meaning is more strongly tied to its social context of acquisition or use." Consequently, students are provided with access to specific content in disciplinary knowledge rather than the disciplinary system of meaning. A focus on specific content does not provide students with the criteria needed to select the knowledge needed in new contexts. Content is disaggregated so that it consists of isolated 'bits' of knowledge. A focus on specific content for a specific context means that the meaning of that content is exhausted by the context. For example, apprentice motor mechanics will have difficulty understanding when and if they should use particular mathematical formulas in other contexts if they have been taught that this particular formula is used in a particular context. They will be able to relate the specific context and the specific formula, but will not have been provided with the tools to choose, select and apply other formulas within that context or a range of other contexts. Knowledge is not under their control.

Critical realism extends these Bernsteinian insights, because a focus on the specific content of disciplines denies students access to the 'collective representations' that provide access into the stratified and emergent nature of the real. This 'absence' arises from the atomistic, empirical ontology and epistemology of CBT. CBT collapses the domain of the real (of generative mechanisms) and the domain of the actual (where 
events take place) into the domain of the empirical (that which is observable). It does this by focussing on the knowledge and skills that people need to 'do' their job and by insisting that assessment be directly aligned with these outcomes rather than the generative mechanisms (and their interplay) that produce those outcomes. One of these generative mechanisms is knowledge, in which the general is recruited to understand the specific.

Because CBT is based on descriptions of discrete atomistic events, it considers tasks and roles independently of their broader relationship to each other, the workplace or society more broadly, and this means that the same task or role can be identified in many workplaces. The task or role takes on universal properties because it is considered independently and non-relationally. It is the task or role that is unique even if it is applied over many contexts, and it is this that is translated into an unproblematic description within units of competency. There is a presumed 'correspondence' between the task or role that the unit of competency describes, so that the description results in objective statements that incorporates all aspects of the relevant task and role and associated skill. Assessment then becomes a straightforward matter of providing 'evidence' that the specified performance criteria have been met. That which can be specified and measured is measured, that which cannot be specified is not measured. The limits of the real thus become defined by the limits of language. ${ }^{6}$ Units of competency are then added up, moved about, and reconfigured to make different qualifications through common core competencies (and employability skills). That is, the total equals the sum of the parts, and different sums (comprising many of the same elements) make different totals. This is the method that aggregates, and is less concerned with understanding the relationship between elements, and how these elements are transformed in the context of such a relationship.

Consequently, despite claims that CBT is premised on contextualised learning, the only real contextualisation is in the way in which competency is demonstrated, not in defining the task or role itself. This is a positivist, atomistic understanding of skill and the elements that contribute to it. Constructivists also critique CBT because it is premised on a limited, positivist notion of contextualised learning, however, as we will see, the 'solution' is to tie learning and knowledge even more tightly to contexts rather than emphasising the transcendental features of knowledge (see Hager and Smith 2004: 39).

In collapsing the domains of the real and actual into the empirical, CBT assumes that outcomes can be achieved by directly teaching to the outcomes, and in doing so ignores the complexity that is needed to create capacity, and this goes beyond the level of experience in the contextual and situated, while not ignoring the importance of such experience. Capacity implies the possibility of responding appropriately to that which has not yet happened, as well that which has. Absences can be conceptualised and alternative realisations envisaged. However, envisaging alternative futures requires access to knowledge. In focussing on aggregations of specific skills, CBT limits the focus to what people have demonstrated they can do in one context, not what they know or could potentially do through creatively and innovatively considering how they can use what they know. In contrast, CBT

\footnotetext{
${ }^{6}$ And instrumentalism shares this feature with constructivism, as illustrated in the next section.
} 
downplays the importance of knowledge as a causal mechanism by emphasising skill as demonstrated through observable outcomes. It also (ironically) downplays the importance of embodied and tacit knowledge because such knowledge does not easily translate to demonstrable and observable outcomes that can be measured and specified.

CBT's simplistic and atomistic notion of skill is what allows current state and Commonwealth government policy in Australia to insist that apprenticeships can be shortened. However, learning how to become a member of a trade, occupation or profession is not simply a matter of meeting all the specified learning outcomes, particularly when these are tied to specific tasks or roles. The holistic development of the person in the context of their profession is excluded, and this involves forming an identity as part of that profession. This cannot be easily codified as observable outcomes tied to specific skills. Bernstein (2000: 59) explains that “This identity arises out of a particular social order, through relations which the identity enters into with other identities of reciprocal recognition, support, mutual legitimisation and finally through a negotiated collective purpose.” The emphasis on specific skills means that the importance and complexity of vocational knowledge recedes and becomes ephemeral, not only in the way in which knowledge is used to orient to work, but also in the role that knowledge plays in forming professional identities. Teaching and learning must engage the real and the actual and not just the empirical, because this is the only way to generate a varying and contextually sensitive performance in a variety of contexts, and to build capacity for dealing with the future.

By focussing on workplace roles and tasks rather than holistically preparing students for an occupation, CBT abstracts knowledge and skill from the bodies of those who must apply that knowledge and skill. People apply knowledge and skill, and education and training needs to address the enabling conditions that allow them to engage in knowledgeable and skilful work. One of the structuring mechanisms that shape particular workplace contexts is the broader knowledge and skills that workers bring with them as well as the way that they apply that knowledge and skill. This is why the aims of education and training should be to develop the knowledge, skills and capacities of workers and citizens in broad terms.

\section{Constructivism}

Constructivism is related to instrumentalism in two ways. The first is, as Moore (2007: 35) explains, because each is committed to a foundationalist notion of truth and justified true belief, in which there is a correspondence between objects and our knowledge of those objects with the possibility of law-like statements about their operation. The difference is that whereas positivism thinks that access to such knowledge is possible, constructivism denies that it is so. Moore (2007: 35) explains that for positivism " ‘things' give order to words” whereas for constructivism "words give order to 'things'.” In constructivism, different words (and different meanings) consequently invest different kinds of order in things, none of which is more true than others because 'the ordering' of social reality is constructed through discourse and the meaning that actors invest in these creative acts. 
The second way in which instrumentalism and constructivism are related is through their commitment to experience as the basis of knowledge. Unlike the empiricism (and positivism) of CBT, constructivists do not restrict themselves to the empirical world, while still privileging experience as the basis of knowledge. Constructivism's focus on contextualised social practices and processes of meaning-making means that the empirical world recedes in importance (where the existence of the empirical is admitted at all). Constructivists are generally not guilty of atomism in the same way as is empiricism, except as in some versions when considering the natural world (Bhaskar 1998a). Constructivism shares with positivism a commitment to "the use of the category of experience to define the world. This involves giving what is in effect a particular epistemological concept a general ontological function” (Bhaskar 1998a: 21). The limits of the world become identified with our knowledge of the world.

The result is that both CBT and constructivism are not able to distinguish between knowledge of objects and the objects of knowledge. Bhaskar (1998b: 142) explains that knowledge of objects and the objects of knowledge are causally related, but they are not the same. The objects of our knowledge have properties that are not dependent on what we think about them, while our access to such objects is through our socially mediated engagement with them, and we use socially produced knowledge as one mechanism of engagement. Knowledge and objects thus have different properties and each may require different forms of access, using different procedures (Bhaskar 1998b: 142). So while we may use knowledge about objects to understand those objects, a condition of using knowledge in that way may require access to previously existing knowledge. For example, the use and application of mathematical knowledge to understand an object requires some understanding of the nature of mathematical knowledge itself, how it is constructed and how it can be used. Knowledge differs from the object it is about because it is a "social product much like any other... which has its own craftsmen, technicians, publicists, standards and skills and which is no less subject to change than any other commodity" (Bhaskar 1998a: 16). However, as Bhaskar (1998a: 16) explains, the other side of knowledge is that it is of things that exist independently of our thoughts about them. Knowledge is therefore not arbitrary because it is causally related to its object, but it is also fallible, because it is a social product and as such dependent for its production on many factors, including the preexisting state of knowledge.

The consequence is that gaining access to knowledge and using that knowledge to gain access to objects are two distinct but related processes. Since knowledge and objects have different properties, processes of gaining access to each may not take place at the same time, because knowledge must exist (have been socially produced) if we are to use it and change it. Bhaskar (1998a: 44) explains that "if all our knowledge is acquired in perception and perception constitutes the world, there can be no place for an antecedent cause of knowledge (or of perception)." Knowledge consists of "antecedently established facts and theories, paradigms and models, methods and techniques of inquiry available to a particular school or worker" (Bhaskar 1998a: 16). The production of new knowledge depends in part on knowledge-like antecedents (Bhaskar 1998a: 17), because without it, we could not use it to explore "the unknown (but knowable) ... structure of the world" (Bhaskar 1998a: 18). In insisting on the causal, but non-identical relation between the object of knowledge and knowledge of the object, Bhaskar (1998b: 146) explains that: 
“...this has the profoundly anti-Cartesian implication that no moment ever contains its own truth, or act its own criteria of intelligibility. In particular, society is not constituted by the way it makes itself intelligible to itself...”

In focussing on the contextual, constructivism seeks to find the criteria of intelligibility within that context - the conditions for intelligibility are identical with the context, and the possibilities of the real are identified with the limits of experience of the context. This leads constructivists to a stronger emphasis on context than is the case with CBT. Learning outcomes are not (generally) divorced from processes of learning, because, according to Hager and Smith (2004: 35), "both the nature of work processes, as well as the standards that are applicable to those processes, are significantly shaped by contextual influences.” They explain that socio-cultural approaches focus "on processes rather than entities or structures, and [stress] the inseparability of the individual and the social” (Hager and Smith 2004: 35). They argue that a focus on context leads to an integrated notion of competence, because knowledge, skills, abilities and attributes are not demonstrated atomistically, but through complex, intentional actions that simultaneously enact several competencies but which at the same time demonstrate situational understanding (Hager and Smith 2004: 37).

Situational understanding is thus contextualised and intersubjective, and this reduces all that is important to the intersubjective in ways that exclude the importance of (and reality of) theoretical knowledge. To insist on the externality and reality of knowledge is to be guilty of reification. The emphasis instead is placed on process and tacit knowledge and skill, and the way in which the social construction of both authorises a performance in one instance as skilled and in another as unskilled (and does not address the question of whether or not the performance really is skilled). The focus becomes the way in which meaning is constructed and in some versions of constructivism, truth defined intersubjectively in ways that exclude and include.

The problem with this analysis is that it only accounts for part of the context it seeks to describe, because it focuses on a discourse that is internal to itself and devoid of external referents. It focuses on the community of producers and how they understand what they are doing, and not on their actual practice - or what they are doing. Both aspects need to be analysed if the nature of practice is to be understood. As Moore (2006: 123) explains, “The fact that all human embeddedness, consciousness and action is, in the first instance, local does not mean that it is nothing but local." In focussing on the contextual, constructivists must discount the way in which social and cultural structures provide the parameters for agential activity by setting the 'degrees of freedom' which facilitate or impede purposeful agential action, and the interplay between the social, material and natural worlds. The domain of the real is discounted, and only the actual and empirical admitted, because to admit that social and cultural structures exist independently of processes of instantiation by agents is to be once again guilty of the sin of reification.

\section{Conclusion}

CBT and constructivism both fail to identify that which is important about contexts which is that students must be able to learn to distinguish theory and contexts if they 
are to recognise and determine contextually appropriate applications of that theory (Clarke and Winch 2004: 517). The capacity to recognise contexts and to appropriately apply theories cannot be solely learnt in the classroom, because students need to learn to relate the general to particular instances and different kinds of instances. This means that learning for the workplace must include learning in the workplace, but that learning cannot be limited to the workplace. The task of vocational pedagogy is to 'face both ways' to theory and the workplace as the basis for their integration in vocational practice (Barnett 2006).

Bhaskar's (1998b: 146) argument that "no moment ever contains its own truth, or act its own criteria of intelligibility" has important implications for pedagogy. By seeking meaning within the contextual, constructivism and instrumentalism deny students access to the conditions of knowledge needed to understand the contextual. This is because the complexity contributing to the structuring of the contextual is denied, as is the means to access to the contextual by using the general to understand the particular. Not all knowledge that we need to use emerges from practice (Young 2008), and we need the means to move beyond the contextual to access systems of knowledge and their generative principles. If the world is characterised by ontological depth, stratification, emergence and co-determination then students need to understand these processes, and not have their understanding restricted to the level of events or experiences.

Neither CBT nor constructivism can theorise the relationship between theoretical knowledge and workplace practice, and consequently for the complementary roles of educational institutions and the workplace and the kind of knowledge that is available in each. Blurring the distinctions between each results in segmental pedagogies, in which knowledge is decontextualised from the system of meaning in which it is embedded, and knowledge becomes tied to the contextual. Students do not have access to the criteria they need to select knowledge and use it in new and creative ways, and knowledge is not under their control.

While CBT has appropriated the language of progressivism and student-centredness from constructivism in legitimating and justifying itself, constructivism has aided and abetted in this process through the commitment it shares with CBT to the contextual and the experiential. The key criticism constructivism makes of CBT is the atomistic way in which the latter conceives of contexts and skills. However, the alternative offered by constructivism is to tie knowledge more tightly to the contextual and, as a consequence, constructivism is not able to mount a coherent critique of instrumentalism or CBT. This is because the most important feature of each approach is the privileging of horizontal discourse over vertical discourse. Consequently, both are complicit in locking VET students out of access to disciplinary knowledge.

\section{References}

Barnett, Michael (2006), Vocational knowledge and vocational pedagogy, in Young, M. and Gamble, J. (eds.), Knowledge, Curriculum and Qualifications for South African Further Education, Cape Town: Human Sciences Research Council. 
Bates, Inge (1998), "Resisting 'Empowerment' and Realizing Power: an exploration of aspects of the GNVQ," Journal of Education and Work, 11, (2): 187-204.

Bates, Inge, Bloomer, Martin, Hodkinson, Phil and Yeomans, David (1998), "Progressivism and the GNVQ: context, ideology and practice," Journal of Education and Work, 112: 109-126.

Bernstein, Basil (2000), Pedagogy, Symbolic Control and Identity, 2nd, Oxford: Rowman \& Littlefield Publishers.

Bhaskar, Roy (1998a), Philosophy and Scientific Realism, in Archer, M., Bhaskar, R., Collier, A., Lawson, T. and Norrie, A. (eds.), Critical Realism: Essential Readings, London: Routledge.

Bhaskar, Roy (1998b), The Possibility of Naturalism: A Philosophical Critique of the Contemporary Human Sciences, 3rd, London: Routledge.

Bloomer, Martin (1998), "'They Tell You What to Do and Then They Let You Get On with It': the illusion of progressivism in GNVQ," Journal of Education and Work, 11, (2): 167-186.

Chappell, Clive, Hawke, Geoff, Rhodes, Carl and Solomon, Nicky (2003), High Level Review of Training Packages Phase 1 Report. An analysis of the current and future context in which Training Packages will need to operate, Brisbane: Australian National Training Authority.

Clarke, Linda and Winch, Christopher (2004), "Apprenticeship and Applied Theoretical Knowledge," Educational Philosophy and Theory, 36, (5): 509521.

Collier, Andrew (1994), Critical Realism: An Introduction to Roy Bhaskar's Philosophy, London: Verso.

Collier, Andrew (1998), Stratified explanation and Marx's conception of history, in Archer, M., Bhaskar, R., Collier, A., Lawson, T. and Norrie, A. (eds.), Critical Realism: Essential Readings, London: Routledge, 258-281.

Commonwealth of Australia (2002), THT02 Tourism Training Package Volume 2 of 5, March, Department of Education, Science and Training, Canberra.

Department of Education Science and Training (2006a), Annual national report of the Australian Vocational and Technical Education system 2005, 29 November, Department of Education, Science and Training, Canberra.

Department of Education Science and Training (2006b), Training Package Development Handbook, November, Department of Education Science and Training, Canberra.

Edwards, Richard and Miller, Kate (2007), "Putting the context into learning " Pedagogy, Culture and Society, 15, (3): 263-274.

Foley, Paul (2007), The socio-economic status of vocational education and training students in Australia, National Centre for Vocational Education Research, Adelaide.

Gamble, Jeanne (2006), Theory and practice in the vocational curriculum, in Young, M. and Gamble, J. (eds.), Knowledge, Curriculum and Qualifications for South African Further Education, Cape Town: Human Sciences Research Council.

Goozee, Gillian (2001), The development of TAFE in Australia, 3rd, Adelaide: National Centre for Vocational Education Research.

Hager, Paul and Smith, Erica (2004), "The Inescapability of Significant Contextual Learning in Work Performance," London Review of Education,, 2, (1): 33 - 46. 
Jones, Lynn and Moore, Rob (1995), "Appropriating Competence: the competency movement, the New Right and the 'culture change' project," British Journal of Education \& Work, 8, (2): 78-92.

Maton, Karl (2007), "Segmentalism: The problem of knowledge-building in education, work and life", Paper presented at Explorations in Knowledge, Society \& Education, University of Cambridge, July

Mitchell, John, Chappell, Clive, Bateman, Andrea and Roy, Susan (2006), Quality is the key: Critical issues in teaching, learning and assessment in vocational education and training, Adelaide: National Centre for Vocational Education Research.

Moore, Rob (2006), Hierarchical Knowledge Structure and the Canon: a preference for judgments, in Christie, F. and Martin, J. R. (eds.), Language, Knowledge and Pedagogy: Functional Linguistic and Sociological Perspectives London: Continuum Press.

Moore, Rob (2007), "Going Critical: the problem of problematising knowledge in education studies.," Critical Studies in Education, 48, (1): 25-41.

Muller, Johan (2006), Differentiation and progression in the curriculum, in Young, M. and Gamble, J. (eds.), Knowledge, Curriculum and Qualifications for South African Further Education, Cape Town: Human Sciences Research Council.

Rumsey, David (2003), Think Piece on the Training Package Model, Australian National Training Authority, Brisbane.

Sayer, Andrew (1992), Method in Social Science: A realist approach, 2nd, London: Routledge.

Sayer, Andrew (2000), Realism and Social Science, London: Sage.

Schofield, Kaye and McDonald, Rod (2004a), High Level Review of Training Packages Working Paper 7: Supporting quality teaching, learning and assessment, Australian National Training Authority, Brisbane.

Schofield, Kaye and McDonald, Rod (2004b), Moving on... Report of the High Level Review of Training Packages, April, Australian National Training Authority, Brisbane.

Scollay, Moira (2000), "The VET reforms debate," Campus Review, March 22, Sydney.

Smith, Peter and Blake, Damian (2005), Facilitating learning through effective teaching: At a glance, National Centre for Vocational Education Research, Adelaide.

Young, Michael (2008), Bringing Knowledge Back In: From social constructivism to social realism in the sociology of education, London: Routledge. 